\title{
O Processo de Formação Inicial de Professores de Português para Falantes de Outras Línguas na UTFPR-CT: Integração entre Prática Pedagógica e Teoria
}

\author{
Initial training of Portuguese teachers for speakers of other languages \\ at UTFPR-CT: integrating theory and classroom practice \\ Elisa Novaski Cordeiro* \\ * Universidade Tecnológica Federal do Paraná, UFTPR, Curitiba - PR, 80230901, email: \\ elisa.novaski@yahoo.com.br \\ Fernanda Deah Chichorro Baldin** \\ ** Universidade Tecnológica Federal do Paraná, UFTPR, Curitiba - PR, 80230901, email: \\ f_chichorro@hotmail.com
}

RESUMO: O objetivo deste artigo é fazer uma análise do processo de formação inicial de professores de línguas estrangeiras oportunizado por um projeto de extensão, cujo objetivo é promover o ensino de Português para Falantes de Outras Línguas (PFOL) na Universidade Tecnológica Federal do Paraná (UTFPR), campus Curitiba. Para tanto, será apresentado um breve histórico dessa atividade e de sua pertinência dentro da UTFPR, um panorama da situação atual e uma análise da relevância desse programa dentro do curso de Letras da UTFPR. Também serão discutidos os conceitos de professor reflexivo (PERRENOUD, 2002) e do trabalho docente baseado na indissociação entre prática e teoria (GIMENEZ, 2005).

PALAVRAS CHAVE: Formação inicial de professores de línguas estrangeiras; Português para falantes de outras línguas; Curso de letras.

ABSTRACT: The purpose of this article is to analyze the initial training of foreign language teachers within an extension project, whose goal is to promote teaching Portuguese for Speakers of Other Languages (PFOL) in the Federal University of Technology- Paraná ( UTFPR), Curitiba Campus. Thus, a brief history about the activities developed in the program will be presented as well as its relevance within the university. Also, an analysis of the program and its current status within the Language and Literature undergraduate course - UTFPR will be discussed. Finally, concepts of reflective teaching (Perrenoud, 2002) and teaching based on the indissociation between practice and theory (GIMENEZ, 2005) will be brought up.

KEYWORDS: Initial training of foreign language teachers; Portuguese for speakers of other languages; Language and Literature undegraduate course. 
O ensino sistematizado de Português para Falantes de Outras Línguas (PFOL) remonta à década de 80 em nosso país. Foi nessa época que surgiram os primeiros materiais didáticos de português para estrangeiros e também houve os primeiros encontros e congressos nos quais pesquisadores da área de Linguística Aplicada se encontraram para discutir o português como língua não materna. Desses encontros, vários livros - com as discussões produzidas por eles - foram publicados. Na década de 90, com a instituição do Celpe-Bras, houve novo impulso ao ensino de português para estrangeiros.

A partir dos anos 2000, mais especificamente desde o começo da segunda década desse século, o perfil de estrangeiros que estudam português no Brasil se modificou, tendo sido fundamental para isso a chegada de sírios e haitianos que aqui reconstroem sua vida. A formação de professores capacitados a ministrar aulas de português a esse público de estrangeiros (bem como outros já conhecidos, tais como intercambistas estudantes do Ensino Médio ou universitários e profissionais de multinacionais) tem merecido uma atenção maior, visto a necessidade de atender a essa demanda até agora crescente.

No presente artigo, optamos por subverter a maneira tradicional de apresentação do artigo. Ao invés de apresentarmos os pressupostos teóricos que norteiam nosso trabalho como professoras formadoras na Universidade Tecnológica Federal do Paraná (UTFPR), escolhemos apresentar nosso contexto, na primeira seção, intitulada " $\mathrm{O}$ PFOL na UTFPR". Traçamos, nessa seção, um breve panorama histórico da organização da oferta de cursos de extensão de PFOL em nossa instituição. Na segunda seção - "PFOL e o curso de Letras da UTFPR" - listam-se as principais atividades de formação realizadas por nosso grupo, deixando clara nossa preocupação com o tripé universitário: ensino, pesquisa e extensão. Na terceira seção, "Teoria e prática na formação inicial de professores", construímos a partir do referencial adotado nossas maiores preocupações com a formação inicial docente, esclarecendo que partimos da indissociação teoria e prática. "O processo de reflexão e conscientização na formação docente", na quarta seção, apresentamos nossa adesão pela perspectiva de formação de professor reflexivo, consciente, ativo, construtor de sua autonomia. Na última seção, "A formação de professores de línguas e o PFOL na UTFPR”, levantamos de que modo 


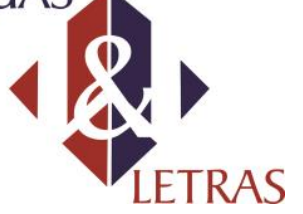

nosso trabalho como formadoras de professores de língua é concebido e como ele se reflete no trabalho que vem sendo desenvolvido no projeto de PFOL.

\section{O PFOL NA UTFPR}

O ensino de português para estrangeiros se iniciou na UTFPR em 2001. Na época, seu objetivo era atender a comunidade interna do então Centro Federal de Educação Tecnológica do Paraná (CEFET). O público predominante era de alunos intercambistas provenientes de instituições internacionais (europeias e latinoamericanas) (BECKER et all, 2011).

Quando surgiu, o curso era ministrado por professores do então Centro Acadêmico de Línguas Estrangeiras Modernas (CALEM) que, mais tarde, transformouse no atual Departamento Acadêmico de Línguas Estrangeiras Modernas (DALEM). No segundo semestre de 2009, o curso de PFOL passou por uma transformação importante: a inclusão de alunos licenciandos de Letras Português Inglês para auxiliar e ministrar aulas, bem como para ajudar na preparação de material didático. Com essa nova configuração de trabalho, foi necessária também a criação de um grupo de pesquisa que auxiliasse tanto os universitários como os professores a trabalhar com as questões inerentes à prática pedagógica (BECKER et all, 2011).

Com o passar do tempo, esse projeto foi crescendo e, graças ao trabalho de alguns professores atuantes nesse desafio, hoje, são atendidos vários estrangeiros, alunos da universidade ou não, sem custo, divididos em cinco níveis (PFOL 1, 2, 3, 4, 5), com ofertas de turmas de 60 horas, em regime semestral.

Atualmente, o projeto continua atendendo aos alunos estrangeiros da UTFPR, mas, agora, também, atende ao público externo. Dessa forma, além de representar um apoio social aos alunos estrangeiros que procuram a universidade, esse projeto traz diversas vantagens. Uma delas se relaciona diretamente aos licenciandos de Letras da UTFPR, já que esses estudantes têm a oportunidade de atuar como monitores voluntários durante as aulas de PFOL junto a um professor orientador. Os acadêmicos de Letras, futuros professores de línguas estrangeiras, assistem às aulas e ministram algumas delas (sempre sob coordenação, orientação e supervisão do professor da turma), preparam atividades, ajudam na elaboração de provas, participam ativamente de todos os trabalhos inerentes à atividade pedagógica, e como mencionado, acompanhados por um professor concursado da instituição - que lhes oferece apoio e 


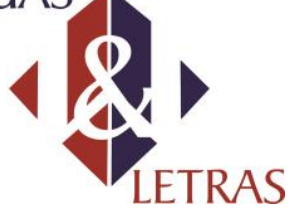

orientação tanto em relação à prática didática quanto à formação teórica no que concerne ao ensino de língua estrangeira e ao ensino de PFOL.

A média de trabalho exigida desses alunos é de seis horas semanais, sendo quatro em sala, acompanhando os alunos de PFOL e duas de orientação entre aluno de Letras e professor orientador. O aproveitamento dessas duas horas fora de sala fica a critério do acordo estabelecido entre ambos, mas, geralmente, elas são usadas para discussões sobre textos teóricos - que venham a auxiliar na prática - e preparação de materiais e de aulas.

O primeiro contato do acadêmico passa pela observação: ele frequenta as aulas de PFOL e as observa, participa da leitura e discussão de textos teóricos, faz a monitoria em atividades individuais ou de pequenos grupos e, pouco a pouco, vai sendo convidado a propor atividades para todo o grupo durante as aulas. A princípio, então, pode ajudar na correção de um exercício, auxiliar nas atividades em dupla, explicar algum conteúdo gramatical, pesquisar diferentes temas para as aulas, ajudar na elaboração de materiais e de provas. Gradualmente, o professor orientador lhe dá maiores responsabilidades: preparar e ministrar uma aula, preparar conjuntamente parte de um exame (pensar em como abordar diferentes temas, criar questões relacionadas ao uso da língua, formular uma grade de correção, etc.) para discussão com o orientador, elaborar atividades que contemplem diferentes habilidades (compreensão oral e escrita e/ou produção oral e escrita).

Atualmente, há cinco professores concursados que participam do grupo de pesquisa do PFOL, desses há três professores que vem trabalhando diretamente com as turmas de PFOL e com os acadêmicos de Letras. O professor que assume turmas durante o semestre é responsável por ministrar aulas de PFOL aos estrangeiros e acompanhar e orientar um grupo de acadêmicos de Letras. A orientação tem duas frentes: o trabalho voltado à prática didática e o estudo da teoria, cujo objetivo é a retroalimentação da prática. Em outras palavras, interessam-nos questões que advêm da relação didático-pedagógica em sala de aula, por isso, os textos de estudos dos monitores voluntários se voltam para questões que aparecem em sala de aula, no intuito de aprofundar as discussões que aparecem como situações na própria dinâmica da sala de aula.

O objetivo da indissociação - prática e teoria - é proporcionar aos universitários a experimentação do cotidiano do professor que, além de planejar, preparar, ministrar e avaliar sua prática, preocupa-se em buscar sua formação continuada através de pesquisa 


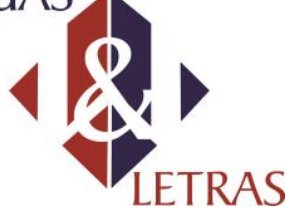

e de tecnologias capazes de auxiliá-lo a entender e a superar os desafios inerentes ao trabalho de ensinar e aprender.

\section{PFOL E O CURSO DE LETRAS DA UTFPR}

Como já mencionado, o PFOL teve sua primeira reconfiguração em 2009, quando acadêmicos de letras passaram a atuar nas aulas regularmente. Nessa mesma época, foi criado o grupo de estudos do PFOL. A partir de então, os alunos de letras passaram a participar das aulas e a desenvolver trabalhos acadêmicos sobre a prática do PFOL.

A partir do primeiro semestre de 2013, deu-se um importante passo para oficializar o trabalho de formação de professores que já vinha sido desenvolvido no grupo: institui-se de modo oficial a monitoria de sala dos acadêmicos de Letras Português Inglês. Percebeu-se, nesse momento, a necessidade de organização do trabalho de formação docente. Para tanto, foi realizado um curso de introdução ao ensino de PFOL (intitulado "Português Língua Estrangeira (PLE): uma introdução à área") e a criação de um Grupo de Trabalho (GTPFOL) com encontros semanais, que oportunizava discussões sobre ensino e aprendizagem de PFOL desde o teste de nivelamento, passando pela escolha do material didático base, ao planejamento do curso e das aulas e à avaliação tanto das processual e diagnóstica quanto pontual.

No segundo semestre de 2013, o trabalho se intensificou com a participação de mais monitores diretamente em sala. O Grupo de Trabalho analisou livros didáticos, selecionou e produziu mais materiais para as aulas e aprofundou o trabalho de estudo sobre questões de sala de aula. Os estudantes de Letras participaram de um curso sobre o exame Celpe-Bras ${ }^{1}$ e realizaram, junto com os alunos estrangeiros, simulados do exame. A partir dos resultados, houve várias discussões que levaram em conta a perspectiva de língua trazida pelo Celpe-Bras em suas Partes Coletiva (Escrita) e Individual (Oral). ${ }^{2}$ Houve também a necessidade de se elaborar, junto com os

\footnotetext{
${ }^{1} \mathrm{O}$ exame Celpe-Bras é um exame de proficiência da língua portuguesa falada no Brasil. De acordo com suas diretrizes, ele tem base comunicativa e o candidato é avaliado por meio da realização de tarefas, tais como resposta a uma carta, preenchimento de um formulário, compreensão de um artigo de jornal ou de um programa de televisão. Não há questões de gramática ou de vocabulário, pois busca-se aferir a capacidade de uso da língua, uma vez que a competência linguística se integra à comunicativa. (BRASIL, 2006, p. 3).

${ }^{2}$ Conceito de tarefa: As tarefas que compõem a Parte Coletiva do exame substituem os tradicionais itens ou perguntas e abrangem mais de um componente. Fundamentalmente, a tarefa é um convite para interagir com o mundo, usando a linguagem com um propósito social. Em outras palavras, uma tarefa

Volume 18
}

Número 39 


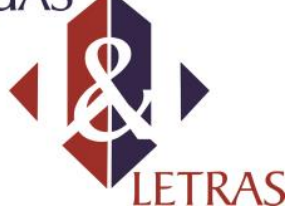

e-ISSN: $1981-4755$

DOI: $10.5935 / 1981-4755.20170006$

acadêmicos, um questionário de perfil do aluno estrangeiro a ser aplicado no exame nivelamento $^{3}$, bem como as atividades propostas para esse mesmo exame. Foi também nesse semestre que houve uma separação mais formal dos níveis oferecidos no curso de PFOL da universidade (cinco níveis, como já mencionado). Foi confirmada escolha do livro didático Novo Avenida Brasil para o eixo do trabalho nos três primeiros níveis, ficando os níveis quatro e cinco para um trabalho mais diretamente focado ao CelpeBras.

No primeiro semestre de 2014, houve um maior aprofundamento dos estudos no grupo de trabalho em relação a questões concernentes à gestão da sala de aula. Foi organizado o I EPFOL da UTFPR (I Encontro de Português para Falantes de Outras Línguas: cenários e desafios) e foi defendido um dos primeiros TCCs (Trabalho de Conclusão de Curso) sobre PFOL de um aluno de Letras da UTFPR.

No segundo semestre de 2014, foi elaborado o Projeto de Extensão do Curso de PFOL na UTFPR, o que garantiu um aumento da oferta de turmas: de uma para quatro. Foram elaborados também, com os acadêmicos de Letras, um estudo sobre refúgio visto que parte considerável dos alunos era constituída por estrangeiros em situação de refúgio ou com visto humanitário - e várias atividades de oralidade. Nesse semestre, houve a defesa de mais alguns TCCs de autoria de alunos de Letras que versavam sobre diferentes aspectos do PFOL. Além dessas atividades, foi firmado um convênio com a universidade colombiana La Sabana. O acordo possibilitou que três alunos de Letras de nossa Universidade fossem à Colômbia trabalhar como funcionários da referida instituição, atuando como professores de português durante o período de um ano 4 .

No primeiro semestre de 2015, a oferta de quatro turmas se manteve. Houve um aumento do número de grupos de trabalho, já que outros professores orientadores entraram no grupo. As discussões nos grupos variaram entre os seguintes temas: questões relativas ao trabalho da oralidade em sala, o exame Celpe-Bras e a elaboração de atividades baseadas na aprendizagem colaborativa. Houve assistência aos alunos estrangeiros que prestariam o Celpe-Bras, participação e apresentação dos acadêmicos

envolve basicamente uma ação, com um propósito, direcionada a um ou mais interlocutores. (BRASIL, 2006, p. 4)

${ }^{3}$ Antes de iniciar o semestre letivo, os alunos estrangeiros participam de um exame de nivelamento que tem por objetivo classificá-los de acordo com seu nível de proficiência da língua portuguesa. O objetivo é tentar deixar as turmas o mais homogêneas possível em relação aos conhecimentos dos alunos estrangeiros.

${ }^{4} \mathrm{O}$ convênio dura até hoje. Os três alunos que formaram o primeiro grupo já cumpriram o contrato de um ano. Um esteve por um ano e meio. Há, no momento, quatro estudantes de Letras na Universidade de La Sabana trabalhando como professores de português para os estudantes dessa instituição.

Volume 18

Número 39 
de Letras no CIEL (I Congresso Internacional de Estudos em Linguagem) na Universidade Estadual de Ponta Grossa.

No segundo semestre de 2015, o projeto contou com a participação de 14 alunos de Letras, matriculados em diferentes períodos do curso, desde os períodos iniciais até os últimos. Houve oferta de quatro turmas, sendo uma delas específica aos alunos estrangeiros que gostariam de fazer o exame Celpe-Bras, com práticas de tarefas relacionadas ao Exame. Realizou-se o II EPFOL, com apresentações de trabalhos dos próprios acadêmicos de Letras, frutos de suas investigações durante sua prática de ensino de PFOL.

Dado esse breve histórico do projeto em nossa universidade, pode-se afirmar que a participação dos alunos, apesar de constante, é transitória, uma vez que sempre há participantes que saem ou entram a cada novo semestre. Alguns formam parte do grupo desde o começo, outros entraram depois, saíram, voltaram. Enquanto alguns participam há muito tempo, outros entraram há apenas um semestre.

Apesar da participação flutuante dos acadêmicos, é interessante perceber que esse formato de trabalho lhes proporciona uma troca de experiências e de conhecimentos intensa. Muitas vezes, os professores orientadores verificam que os acadêmicos mais "experientes" auxiliam os colegas "novatos" em situações de conflito e dúvidas. Eles se incentivam, trocam informações e experiências, dividem dúvidas, o que criou (e cria) um ambiente de aprendizagem baseado na interação e no auxílio mútuo.

O fato de os alunos de Letras pertencerem a diferentes períodos letivos é outro fator que auxilia na troca de conhecimentos, sendo identificado como extremamente positivo. A troca gerada por essa situação lhes ajuda a compartilhar aspectos teóricos e a vivenciá-los na prática. Constrói-se, dessa forma, uma aprendizagem baseada na colaboração: há um aprendizado por meio da interação e mútua ajuda entre os companheiros (CORDEIRO, 2013).

Um exemplo desse aspecto reside no fato de que as aulas de PFOL propiciam a esses alunos a contestação de suas próprias crenças e concepções em relação ao ensino de uma língua estrangeira. Conceitos como o de falante nativo, de níveis de proficiência e domínio de língua se tornam objetos de reflexão, já que os acadêmicos percebem, na prática, concepções debatidas na teoria. Por exemplo, eles percebem que simplesmente ser falante de português não faz deles professores dessa língua, pois, durante sua 


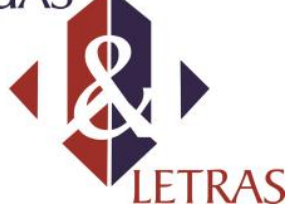

e-ISSN: 1981-4755

DOI: $10.5935 / 1981-4755.20170006$

experiência em sala de aula, evidencia-se a necessidade de uma formação específica na área.

Parece ser muito lógico pensar que um professor brasileiro de PFOL, cuja língua materna é o português, precisará preocupar-se "somente" em ensinar o que já domina perfeitamente: a língua portuguesa. Porém, esse professor, antes de tudo, ensinará sua língua como uma língua estrangeira a uma turma completamente heterogênea, já que seus alunos têm diferentes nacionalidades e diferentes culturas, assim como diferentes repertórios linguísticos. Muitas vezes, esse professor brasileiro de PFOL não compartilha a língua materna de seu aluno. Todos esses aspectos exigirão uma compreensão desse docente de que ensinar português como língua materna é muito diferente de ensinar português como língua estrangeira.

Nesse sentido, Almeida Filho (2005) destaca a importância de uma formação específica para professores de PFOL. O pesquisador esclarece que a prática profissional não pode se limitar a uma prática espontânea, ou seja, ela precisa estar baseada em uma "formação profissional teórica com conhecimento articulado explícito sobre os processos de ensinar e de aprender” (ALMEIDA FILHO, 2005, p. 3 ).

Segundo o mesmo autor, ensinar português como língua materna, tal qual aprendemos na escola nas aulas de língua portuguesa, é completamente diferente de ensinar português para falantes de outras línguas. Cunha (2007) corrobora essa visão, diferenciando o ensino de português como língua materna do ensino de português como língua estrangeira.

Desse modo, os alunos de Letras participantes do PFOL têm uma excelente oportunidade: tornar-se professor enquanto são professores. Do mesmo modo, os professores orientadores percebem uma nova perspectiva em seu trabalho de formadores de professores: orientar a prática de seus alunos e auxiliá-los a resolver embates surgidos durante a própria prática pedagógica. Esse processo gera uma série de trocas: entre os acadêmicos, entre os professores atuantes no projeto, entre os professores e os universitários. Constrói-se, dessa forma, uma rede de apoio e de trocas de experiências e de conhecimentos propiciados por um ambiente de aprendizagem colaborativa, na medida em que todos se auxiliam: professor formador e professor em formação.

Nesse sentido, anula-se a figura tradicional do professor detentor do conhecimento e aparece a imagem do professor mediador: aquele que intervém no processo de aprendizagem. Berni define o professor sob a perspectiva da teoria sóciohistórico-cultural da seguinte forma: "provocador de conflitos; suporte e apoio no 


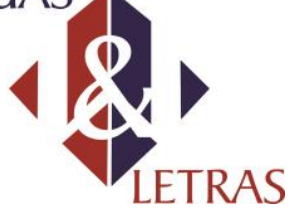

processo; mediador; constrói junto com os alunos; preocupa-se com o processo e não apenas com o produto.” (BERNI, 2008, p. 2535).

Gimenez (2005), da mesma forma, desloca o professor do núcleo central concebido tradicionalmente e coloca o discente em destaque, afirmando que a aprendizagem é um processo que leva em conta o aprendiz professor e seus conhecimentos. Desse modo, não há necessidade de haver um posicionamento da figura de um mediador mais experiente, uma vez que os conhecimentos adquiridos ao longo de experiências anteriores e atuais podem ser articulados e divididos entre todos. Essa compreensão possibilita à educação profissional um caráter interventivo, o que abre espaço para uma negociação e explicitação dos objetivos a serem alcançados.

\section{TEORIA E PRÁTICA NA FORMAÇÃO INICIAL DE PROFESSORES}

Uma das características do projeto PFOL da UTFPR é o trabalho integrado entre teoria e prática, já que não entendemos possível sua dissociação. Busca-se propiciar aos universitários a oportunidade de vivenciar o trabalho docente por meio das atividades que envolvem o cotidiano do professor. O acadêmico é inserido no contexto de sala de aula e se dá conta dos detalhes que envolvem a prática docente, tais como: responder a um questionamento de um aluno; planejar e preparar uma aula, colocá-la em prática e avaliá-la, tendo em vista que faz parte de uma sequência que forma o curso; reformular uma explicação que o aluno estrangeiro não compreendeu; deparar-se com problemas de relacionamento e integração entre os alunos; além de outros detalhes muito mais simples, como, por exemplo: como movimentar-se em sala, como utilizar o quadro de modo claro, como comportar-se durante a aula: tom de voz, demonstração de segurança, criação de outras alternativas de explicação rapidamente, gestão do tempo, programação (e reorganização) da explicação na hora adequada, percepção do momento de interromper uma atividade, por exemplo, para auxiliar um aluno. Todos esses aspectos (como outros) fazem parte de uma postura requerida do docente que exige a prática didática.

O estudo isolado da teoria não dá ao futuro professor condições de perceber todas essas nuances que fazem parte do trabalho docente. Por isso, acreditamos em um trabalho reflexivo na prática, desde o começo da formação inicial para professores: um trabalho que lance o acadêmico na sala de aula, sempre sob coordenação e supervisão, 


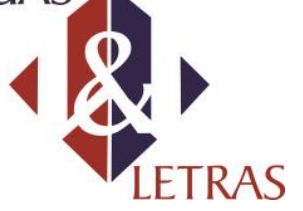

mas que possibilite que ele planeje, crie, produza, aplique, discuta, avalie e reorganize suas crenças, pressupostos, visões e práticas.

Atualmente, grande parte dos currículos de licenciaturas em Letras com habilitação em língua estrangeira estão pensados da seguinte maneira: os três anos iniciais são de teoria e a atividade prática docente é realmente experienciada pelo aluno a partir das disciplinas de prática de ensino e estágio. Gimenez (2005) afirma que, embora as diretrizes de formação de professores destaquem a necessidade de se pensar na prática a partir de todas as disciplinas do currículo, muitas vezes, esse aspecto da formação se resume às atividades inerentes às disciplinas de prática de ensino. Segundo a autora, em geral, o que se percebe é que a teoria direciona a prática, o que representa um paradoxo, já que "professores agem mais de acordo com conhecimentos prévios, crenças, representações e valores do que por interesses em implementar teorias" (GIMENEZ, 2005, p. 189).

No caso do projeto PFOL da UTFPR, pode-se afirmar que os acadêmicos de Letras envolvidos no projeto experienciam o trabalho docente na prática desde o começo de sua participação no projeto, tendo a oportunidade, desse modo, de trabalhar em um contexto de prática indissociada da teoria. Esse é um dos alicerces de nosso trabalho como professores formadores, já que entendemos que um curso de formação de professores não pode centrar-se unicamente em concepções teóricas, que relegam a prática ao último ano de formação somente, focada apenas em um pequeno grupo de disciplinas. Vemos como fundamental que o discente tenha a oportunidade de testar o contexto de sala de aula desde o começo de sua formação. Os acadêmicos envolvidos no projeto podem sentir e viver o contexto de sala de aula/ensino/aprendizagem de modo vivo, pois eles têm a oportunidade de vivenciar o cotidiano de uma sala de aula real e, não um ambiente descrito em livros somente, com a figura do aluno idealizado e situações pré-definidas.

Não é nossa intenção afirmar que a teoria não é importante. Sim, ela é fundamental, mas somente ela não basta para que o futuro professor tenha condições mínimas para exercer sua profissão. Pimenta (2002) afirma sobre a teoria:

O papel da teoria é oferecer aos professores perspectivas de análise para compreenderem os contextos históricos, sociais, culturais, organizacionais e de si mesmos como profissionais, nos quais se dá sua atividade docente, para neles intervir, transformando-os. (PIMENTA, 2002, p. 26) 
Sendo assim, a teoria tem papel essencial na formação de professores, uma vez que, através dela, o professor terá condições de intervir em sua realidade e a transformar. A importância da teoria se dá na mesma medida em que ela pode ser aplicada à prática.

Para um professor de línguas, o estudo da teoria pela teoria não tem muita relevância. $\mathrm{O}$ ideal seria articular o conhecimento teórico e a atividade prática de modo a criar uma base suficientemente sólida para que o aluno seja capaz de desenvolver-se plenamente como professor. Gimenez (2005) aponta um erro muito comum cometido por formadores de professores: imaginar que somente a leitura de textos teóricos seria suficiente para provocar transformações. Quando, na verdade, ela é apenas um dos aspectos a se considerar na formação e não o único, nem como se concebe costumeiramente, o mais importante.

Os acadêmicos participantes do PFOL da UTFPR são levados a perceber que o professor orientador não é aquele que tem todas as respostas, nem aquele que lhes dirá $o$ que fazer ou como dar aula. Mais do que isso, os acadêmicos, futuros professores, são convidados a entrar na sala dos professores e na sala de aula. Em outras palavras: eles participam não só do momento da aula, mas também dos bastidores da sala de aula, que envolvem leitura, estudo, discussão, avaliação: a preparação docente. Dessa forma, os universitários são levados a descobrir como funciona a tarefa de acompanhar o desenvolvimento do aluno e como, na maioria das vezes, as dificuldades da prática nos levam a buscar a teoria a fim de encontrar respostas. Percebendo, assim, que o trabalho do docente não é nem puramente empírico ou intuitivo nem rígido e pré determinado por fórmulas e teorias.

\section{O PROCESSO DE REFLEXÃO E CONSCIENTIZAÇÃO NA FORMAÇÃO DOCENTE}

O termo professor reflexivo foi estabelecido a partir de estudos sobre formação profissional realizados por Donald Schön no início dos anos 1990. De acordo com suas pesquisas, o modelo de formação profissional que prevê a apresentação da ciência e a posterior aplicação dos conhecimentos em um estágio no final do curso não são capazes de dar as respostas necessárias ao futuro profissional em seu cotidiano laboral. Desse modo, o pesquisador sugere que se dê oportunidade, durante a formação, para que o futuro profissional desenvolva a habilidade de refletir constantemente sobre sua prática. 


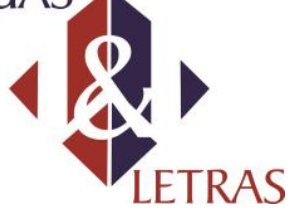

Espera-se uma valorização da prática profissional como momento de construção do conhecimento, por meio de reflexão, análise e problematização (PIMENTA, 2002). Apesar de sofrer críticas, muito do que encontramos em seu modelo de professor reflexivo ainda vem sendo debatido, rediscutido e considerado como válido.

Perrenoud (2002) discorre sobre a importância de se possibilitar um ambiente no qual o profissional em formação tenha a possibilidade de desenvolver a prática reflexiva de modo que ela se torne um componente duradouro em seu habitus, e não somente, restrita à formação inicial. Para tanto, ele não apresenta respostas nem fórmulas prontas, mas afirma que é fundamental que os envolvidos no processo se sintam interessados por atingir esse objetivo. Segundo ele, "se os estudantes esperam respostas categóricas, receitas e rotinas, o empreendimento não poderá ser bem-sucedido" (PERRENOUD, 2002, p. 64). Em outras palavras, o professor formador preocupado em desenvolver uma prática reflexiva em seus alunos necessita muito mais ajudar-lhes a formular perguntas do que a simplesmente fornecer as respostas.

Levando em conta essa visão, possibilitamos ao aluno professor a participação de modo ativo em sua própria formação. Esse é um caminho que poderá ser guiado por seus professores formadores, que, pouco a pouco, irão propiciando ao aluno a oportunidade de direcionar o seu aprendizado. A princípio, essa meta pode parecer bastante utópica, mas Gimenez (2005) aponta a linguística aplicada como um possível caminho para uma formação mais pensada na prática, já que esse é um campo do conhecimento que se preocupa com questões práticas e que reconhece o caráter social da língua. Nas palavras da autora:

Considero que a grande contribuição que a LA [linguística aplicada] traz para os cursos de Letras é a maneira como aborda questões de língua e linguagem, sua preocupação com questões práticas e as visões alternativas sobre o que seja língua na sociedade. Esta perspectiva pode fazer com que futuros professores construam suas visões sobre seu papel na educação pelas línguas. (GIMENEZ, 2005, p. 188).

Perrenoud (2002) afirma que a formação para uma prática reflexiva se consegue, como o próprio nome indica, mediante o exercício da própria prática. $\mathrm{O}$ autor diferencia a prática reflexiva de uma competência que existe a serviço do professor. Mais do que isso, trata-se da expressão da consciência profissional. Segundo o autor, o professor reflexivo não é aquele que reflete somente quando sente necessidade ou insegurança, mas o faz de modo constante, mesmo quando tudo parece estar muito bem. 
Nesse sentido, Furtoso (2001) coloca o professor como um elemento essencial na tomada de decisão a respeito do ensino. Já que, nessa perspectiva, sua função vai além de executar planejamentos, atividades e decisões tomadas por outras pessoas. Tal posicionamento exige muito mais do que um treinamento de professores, já que estes não precisam ser moldados $\mathrm{e}$, sim, preparados para intervir no processo de aprendizagem.

\section{A FORMAÇÃO DE PROFESSORES DE LÍNGUAS E O PFOL NA UTFPR}

A maneira como os acadêmicos de letras da UTFPR participam das aulas de PFOL lhes proporciona uma formação inicial inserida em um ambiente de exposição à prática desde o começo do curso. Essa prática sempre vem aliada à teoria, já que os universitários têm a oportunidade de acompanhar a rotina da sala de aula cotidianamente, e também o estudo de aspectos teóricos relacionados à prática pedagógica. O que pode proporcionar-lhes uma visão muito diferente de suas profissões, uma vez que o contato com a atividade docente é muito mais próximo do que aquele viabilizado pela leitura de textos teóricos exclusivamente.

Nas aulas de PFOL, os monitores entram em contato com as situações, muitas vezes imprevisíveis, do dia a dia de sala de aula, contando com os professores orientadores para auxiliá-los e dar suporte nos diferentes desafios ao longo da prática docente. Eles têm a oportunidade de se desenvolver, pouco a pouco, como futuros professores reflexivos, capazes de refletir e decidir sobre o rumo de seu fazer pedagógico.

Como sua participação é voluntária, percebe-se que há um alto grau de interesse e o que mais lhes motiva é o real contato com a sala de aula, bem como a vontade de interagir com os alunos e de sentir-se e formar-se como professor. Os professores orientadores, por sua vez, têm a chance de intervir diretamente no desenvolvimento desses futuros profissionais e de auxiliá-los a construir-se como docentes e também, de se rever, repensar e reconstruir-se como professores, também relativizando e reavaliando suas crenças, seus valores, suas práticas.

Muito diferente do que acontece nas disciplinas de estágio supervisionado das licenciaturas, nas quais o professor orientador participa somente de duas ou quatro horas aulas ministradas pelo discente, no PFOL, o professor orientador observa o aluno em 


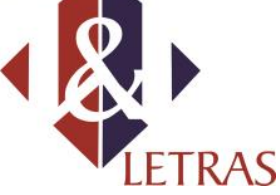

formação por, pelo menos, um semestre letivo mediando seu desenvolvimento como professor em formação inicial e intervindo nele.

Esse tipo de acompanhamento confere um tipo de aprendizagem gerada pela interação entre todos os envolvidos. Em primeiro lugar, os acadêmicos interagem entre si e essa interação lhes ajuda a desenvolverem-se como profissionais capazes de trabalhar em equipe, de dividir dúvidas e de buscar soluções. Em segundo lugar, os professores orientadores interagem entre si, o que gera troca de conhecimentos, de conceitos, discussão de crenças. E a interação entre professores formadores (e em formação continuada) e acadêmicos em formação inicial origina mudanças em todos os envolvidos. Nas reuniões realizadas entre a equipe de professores orientadores, constantemente são contestados, discutidos e reconfigurados nossos objetivos, nosso modo de atuar como formadores, nossas dúvidas e inquietações. Em terceiro lugar, os acadêmicos interagem com seus professores orientadores, o que representa um aprendizado para ambos, já que, o processo de ensinar, nesse caso, imprime um viés completamente diferente do tradicional, uma vez que o professor orientador não será aquele que dirá o que fazer ou como fazer. Mais do que isso, ele conferirá responsabilidades aos acadêmicos e os ajudará a assumir e a cumprir essas responsabilidades, como também será questionado por esses acadêmicos, que também o auxiliam a se pensar como professor.

Esse exercício de exigência é muito importante, já que se trata de uma forma de desenvolver a maturidade desses alunos em formação e, muitas vezes, será o primeiro contato efetivo com uma autonomia que, até então, o discente não conhecia. Quando é dada ao aluno a responsabilidade de preparar um material, uma prova, uma aula, corrigir um exercício, não está em jogo a nota que o professor lhe dará por um trabalho escolar/acadêmico desenvolvido nos moldes tradicionais - inclusive porque em nosso projeto não há atribuição de notas. O objetivo é muito mais do que "passar": o aluno monitor precisa se encarregar de assumir uma responsabilidade perante os seus próprios alunos. Assim sendo, ele muda de posição: ele passa de aluno para professor.

Essa mudança, quando acompanhada por um professor orientador mais experiente, pode ser mais eficaz e frutífera para o futuro profissional do indivíduo em formação. Nosso objetivo é auxiliar o discente a pensar sobre sua própria prática pedagógica e, assim, construir-se como um professor reflexivo, que tem por hábito analisar-se e reconfigurar-se constantemente. 
O trabalho desenvolvido pelo PFOL na UTFPR representa a oportunidade de os acadêmicos de letras experenciarem a prática pedagógica sob um prisma muito diferente daquele oportunizado pela leitura de textos teóricos exclusivamente. Busca-se ajudar o universitário a conhecer efetivamente o trabalho docente desde o início do curso. Assim, ele tem a oportunidade de confrontar-se com as dúvidas, os anseios e as responsabilidades inerentes à profissão.

A teoria dissociada da prática representa uma experiência muito vazia quando comparada a oportunidades como a do PFOL. Nesse projeto, prática e teoria caminham juntas a fim de possibilitar nosso maior objetivo como formadores de professores: o desenvolvimento de profissionais autônomos, cujo saber teórico se reflete em sua prática pedagógica.

\section{REFERÊNCIAS}

ALMEIDA FILHO, José Carlos P. O ensino de português como língua não-materna: concepções e contextos de ensino. Acervo digital do Museu da Língua Portuguesa. 2005.

BALDIN, Fernanda Deah Chichorro. Formação de professores de português para estrangeiros: perspectivas na formação inicial na UTFPR. Curitiba: Fernanda Baldin, 2015. 12, azul.

BECKER, Marcia Regina; BORK, Ana Valéria Bisetto; RETORTA, Miriam Sester; RODRIGUES, Carlos Aurélio Nogarolli; FIGUEREDO, Mariana Galli; QUEIROZ, Valéria Schmid; SILVA, Gisele dos Santos da; BREDA, Suellen Thalyta; VILELA, Carla Prado Lima Silveira. O desafio do ensino de português para falantes de outras línguas - PFOL - na UTFPR. Em: Anais do $1^{o}$ SEI - Seminário de Extensão e Inovação da UTFPR, Curitiba, 2011.

BERNI, Regiane Ibanhez Gimenes. Mediação: o conceito vygotskyano e suas implicações na prática pedagógica. Em: MAGALHÃES, José Sueli de; TRAVAGLIA, Luiz Carlos (orgs). Múltiplas perspectivas em linguistica. Uberlândia: EDUFU, 2008.

BRASIL. Celpe Bras. Manual do Examinando. Novembro de 2015. Disponível em < http://download.inep.gov.br/outras_acoes/celpe_bras/manual/2012/manual_examinando _celpebras.pdf > Acesso em 01/02/2016.

CUNHA, Maria J. C. O português para falantes de outras línguas: redefinindo tipos e conceitos. Em: ALMEIDA FILHO, José Carlos P. CUNHA, Maria J. C. (orgs.) Projetos iniciais em português para falantes de outras línguas. Brasília: Editora UnB, 2007. Pag. 13 a 31.

CORDEIRO, Elisa Novaski. Dissertação de Mestrado: Foco na forma na aprendizagem de espanhol por falantes brasileiros através da aprendizagem colaborativa. Universidade Federal do Paraná. Curitiba, 2013.

FURTOSO, Viviane Aparecida B. Dissertação de Mestrado: Português para falantes de outras línguas: aspectos da formação do professor. Londrina: Universidade Estadual de Londrina, 2001. 


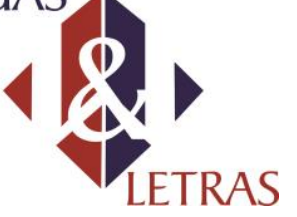

e-ISSN: $1981-4755$

DOI: $10.5935 / 1981-4755.20170006$

GIMENEZ, Telma. Desafios contemporâneos na formação de professores de línguas: contribuições da linguística aplicada. Em: FREIRE, Maximina. ABRAHÃO, Maria H. V. BARCELOS, Ana Maria F. (orgs.) Linguística aplicada e contemporaneidade. São Paulo: ALAB, Campinas: Pontes Editores, 2005. Pag 183 a 201.

PERRENOUD, Philippe. A prática reflexiva no oficio do professor. Porto Alegre: Artmed Editora, 2002.

PIMENTA, S.G. Professor Reflexivo: Construindo uma Crítica. Em: Pimenta, S.G.; GHEDIN, E. (orgs.) Professor reflexivo no brasil: gênese e crítica de um conceito. São Paulo: Cortez, 2002.

Data de recebimento: 08/10/2016

Data de aprovação: 10/05/2017 